\title{
Orientação para enfermagem: no cuidado a criança em conflito de aprendizagem TDAH
}

\author{
Nursing orientation: the child in ADHD learning conflict \\ Orientación de enfermería: el niño en el conflicto de aprendizaje del TDAH
}

\section{Dayse de Fatima Fonseca da Silva ${ }^{1 *}$, Vanessa Cristina de Souza Santos², Diogo Jacintho Barbosa ${ }^{3}$}

Como citar esse artigo. da Silva, DFF; Santos, VCS; Barbosa, DJ. Orientação para enfermagem: no cuidado a criança em conflito de aprendizagem TDAH. Revista Pró-UniverSUS. 2020 Jul./Dez.; 11 (2): 80-88.

\begin{abstract}
Resumo
O presente trabalho se propõe identificar as atuações de enfermagem frente à criança com TDAH. A base metodológica que permeou todo o presente trabalho e se fundamentou no referencial teórico, a partir da análise dos textos consultados das fontes bibliográficas, no enfoque da leitura da TDAH. No cerne desta questão, deve debruçar ao analisar os cuidados de enfermagem em que os resultados alcançados com as crianças com TDAH, ao desenvolver políticas de saúde e suscitou conhecimento pela investigação, e o interesse existencial em torno das questões de TDAH ligado a saúde, a um viver saudável e feliz de uma criança em pleno desenvolvimento. Sendo assim, acolher e escutar são ações esperadas por parte do profissional de enfermagem, em que este se encontra em posição privilegiada, por estar próximo ao paciente. Fica evidente que valorizar e estimular as habilidades e capacidade de aprendizado, para que a criança com TDAH encontrem maneiras de viver no ambiente escolar, e que tragam maior satisfação na sua dinâmica de vida.
\end{abstract}

Palavras-chave: Criança; Enfermagem; TDAH.

\begin{abstract}
The present work proposes to identify the nursing actions towards children with ADHD. The methodological basis that permeated the present work and was based on the theoretical framework, based on the analysis of the texts consulted from the bibliographic sources, in the focus of reading ADHD. At the heart of this question, you should look at analyzing nursing care in which the results achieved with children with ADHD, when developing health policies and raised awareness through research, and the existential interest around health-related ADHD issues, a healthy and happy life for a child in full development. Therefore, welcoming and listening are expected actions on the part of the nursing professional, in which he is in a privileged position, because he is close to the patient. It is evident that valuing and stimulating skills and learning capacity, so that children with ADHD find ways to live in the school environment, and that they bring greater satisfaction in their life dynamics.
\end{abstract}

Keywords: Child, Nursing, ADHD.

\section{Resumen}

El presente trabajo propone identificar las acciones de enfermería hacia niños con TDAH. La base metodológica que permeó el presente trabajo y se basó en el marco teórico, a partir del análisis de los textos consultados de las fuentes bibliográficas, en el foco de lectura del TDAH. En el centro de este problema, debe analizar el cuidado de enfermería en el que los resultados logrados con niños con TDAH, al desarrollar políticas de salud y despertar el conocimiento a través de la investigación, y el interés existencial en torno a problemas de TDAH relacionados con la salud, Una vida sana y feliz para un niño en pleno desarrollo. Por lo tanto, acoger y escuchar son acciones esperadas por parte del profesional de enfermería, en el que se encuentra en una posición privilegiada, porque está cerca del paciente. Es evidente que valoran y estimulan las habilidades y la capacidad de aprendizaje, de modo que los niños con TDAH encuentren formas de vivir en el entorno escolar y aporten una mayor satisfacción en la dinámica de su vida.

Palabras clave: Niño; Enfermería; TDAH.

Afiliação dos autores:

${ }^{1}$ Acadêmica de Enfermagem do Centro Universitário Gama e Souza - UNIGAMA. RJ, Brasil. ORCID: https://orcid.org/0000-0001-7880-5915

${ }^{2}$ Acadêmica do Centro Universitário Gama e Souza - UNIGAMA, RJ, Brasil. ORCID: https://orcid.org/0000-0002-7226-2849

${ }^{3}$ Professor Substituto da Universidade Federal do Rio de Janeiro-UFRJ. Docente do Curso de Enfermagem do Centro Universitário Gama e Souza - UNIGAMA. Doutorando em

Enfermagem na Faculdade de Enfermagem da UERJ. RJ. Brasil. ORCID: https://orcid.org/0000-0001-6171-0768 


\section{Introdução}

A discussão e o interesse existencial em torno das questões de TDAH ligado a saúde, e também levando em conta a um viver saudável e feliz de uma criança em pleno desenvolvimento. Atualmente o Transtorno de Déficit de Atenção e Hiperatividade (TDAH) ainda é um transtorno envolto em inúmeras crianças no âmbito da educação escolar que se caracteriza como uma síndrome que apresenta características como desatenção, impulsividade, desassossego e agitação.

De acordo com a publicação da Organização Pan-americana da saúde (OPAS) ${ }^{1}$, os determinantes da saúde mental e transtornos mentais incluem não apenas atributos individuais, como a capacidade de administrar os pensamentos, as emoções, os comportamentos e as interações com os outros, mas também os fatores sociais, culturais, econômicos, políticos e ambientais.

É preciso ressaltar em reflexões peculiaridades em torno da criança com TDAH, acredita-se na importância do papel do profissional de enfermagem dentro instituição educacional no cuidado da saúde mental desse aluno.

O tema desta pesquisa é relevante, porque tem como foco uma questão bastante atual, numa perspectiva de cuidado, que é a existência de crianças com diagnósticos de TDAH. O fato é que o Transtorno de Déficit de Atenção e Hiperatividade (TDAH) há muitos anos, vem recebendo uma atenção de pesquisadores principalmente das áreas de Educação, Psicologia e Medicina $^{2}$.

Entretanto, o transtorno de déficit de atenção e hiperatividade (TDAH) é uma das doenças psiquiátricas mais diagnosticadas em crianças e seguidas de adolescentes na atualidade, com prevalência calculada em $5 \%$ da população infanto-juvenil. ${ }^{2}$

Portanto, o tema apresentado é pertinente, pois ressalta em análises conjuntas em uma oportuna distinção entre o profissional de saúde e o seu papel dentro da escola. Fica evidente, uma ampla e merecida discussão quanto o trato com crianças com TDAH, a profundidade das interpretações no que diz respeito a saúde mental.

Ao valorizar a criança com TDAH e também como pessoa, preconiza-se que na assistência e no cuidado, é necessária solidariedade e apoio social. Nesse contexto, o problema que norteou a pesquisa vincula-se à análise que tratará de pesquisar: Qual a importância da orientação da enfermagem na avaliação da criança e da família frente ao conflito de aprendizagem devido TDAH?

Diante desse quadro, acredita-se que com o diagnóstico e tratamento correto, os problemas tais como: repetência escolar, abandono dos estudos, transtornos comportamentais podem ser adequadamente tratados, a partir da perspectiva do cuidado da saúde.
Este trabalho é de suma importância para entender a relevância do profissional de enfermagem diante de crianças com transtornos de TDAH na atenção primária a saúde, dentro de uma instituição educacional e pela sua finalidade em contribuir para o desenvolvimento da prática profissional e definição de sua função neste contexto.

Com efeito, a produção desta pesquisa parte dos anseios e situações vividas enquanto profissional técnico de enfermagem, exercendo a função de assistência da saúde, na atenção primária a saúde dos alunos. Situações estas que ocasionaram inquietações, indagações e dúvidas quanto à definição do papel do profissional de enfermagem na visão da educação a partir de suas ações.

O contato com educandos infanto-juvenil na unidade educacional, onde se dá atenção primária e a vivência neste campo como assistente de saúde, instigou-me a promover a execução deste trabalho de forma a buscar entender como, lidar com os transtornos de TDAH, na concepção da função do profissional de enfermagem sob a ótica de contribuir para saúde mental da criança.

Dessa forma essa pesquisa, espera-se identificar o preparo do profissional de enfermagem diante das situações TDAH enfrentadas para efetivar sua atuação.

Com base nestas premissas, foi definido como questão de pesquisa: Quais os conhecimentos necessários para o cuidado à criança com TDAH?

Com o intuído de responder a esta pesquisa, foi elencado os seguintes objetivos: identificar as orientações de enfermagem para a criança e a família frente ao conflito de aprendizado devido TDAH; e discutir os benefícios das orientações de enfermagem para a criança e a família frente o conflito de aprendizado devido o TDAH.

\section{Metodologia}

A base metodológica que permeia todo o presente trabalho e se fundamenta no referencial teórico, a partir da análise dos textos consultados das fontes bibliográficas ${ }^{3}$, no enfoque da leitura da TDAH.

Foi realizada uma busca na literatura utilizandose a BVS (Biblioteca Virtual em Saúde), para qual foram utilizadas as seguintes palavras chave: enfermagem; TDAH, saúde mental, Educação. Após a coleta de dados e reunião de literaturas, houve uma seleção do material de acordo com o objeto de estudo.

Os critérios de inclusão basearam-se em artigos no idioma português, com texto disponível completo de maneira gratuita e publicado em 2004 a 2019

\section{Resultados}

A partir da análise das coletas de dados, e para um melhor detalhamento, verificou-se que conteúdos 
relacionados ao tema: Orientação da enfermagem: "A criança e o conflito de aprendizagem TDAH", que foram estabelecidos na tabela 1. No entanto, foram identificados 24 artigos utilizando-se os critérios de busca. Seguiuse, então, com a leitura dos títulos para realizar a préseleção a partir dos critérios de inclusão estabelecidos, resultando num total de 9 artigos selecionados para o estudo. Salienta-se que serão apresentados a seguir a discussão dos resultados, em que os mesmos obtidos foram confrontados com as práticas utilizadas pela assistência de enfermagem no âmbito da saúde mental e a promoção da saúde do infante, com os autores debatedores dos assuntos abordados.

$\mathrm{O}$ resumo dos principais resultados dos artigos que compõem a amostra final deste estudo podem ser encontrados na tabela 2

Foram incluídos artigos da área da saúde, sendo estas áreas: Enfermagem, Psicologia que continham a temática do TDAH na criança. Nesta etapa do trabalho, foi caracterizada a demonstração dos dados achados a partir da revisão teórica que foram apresentados por meio de tabela, bem como a análise dos resultados e discussão. Após seleção dos títulos mencionados acima pela disponibilidade do texto completo a respeito do TDAH no dispositivo online e ano das publicações.

A amostra de estudo foi composta por 24 publicações com intuito de se obter a amostra representativa de cada publicação, em que foram encontradas frente a esses critérios de inclusão pela qual foram selecionados para esta pesquisa foram encontrados 16 estudos de enfermagem na área TDAH, e 8 estudos na área de psicologia voltado para o tema. Em relação às publicações no contexto da enfermagem está entre 2011 e 2017. Para psicologia o ano está entre 2007 e 2016

\section{Discussão}

Neste item são apresentados os resultados obtidos a partir da análise das publicações que compõem essa pesquisa. Contudo, os resultados trazem a discussão sobre quais as orientações de enfermagem realizadas para o atendimento de crianças frente ao conflito de aprendizado devido TDAH. Os quatros estudos abordam formas diferentes de apresentar as ações de enfermagem praticadas com crianças.

É importante lembrar a observação do estudo conduzido pelos autores que afirmaram que atenção básica em enfermagem no âmbito da saúde mental, que está em foco na atualidade ${ }^{5}$. Deve-se entender levando em conta também a demanda do profissional de enfermagem em uma posição de agente terapêutico. Com base na análise das informações colhidas, podese ressaltar a fragilidade da atuação do profissional de saúde, neste caso o profissional de enfermagem.

É certo que o cuidado com pacientes crianças que em muitos dos casos que apresentam aspectos patológicos na atenção á saúde. No entanto, os momentos de manifestações da crise TDAH por uma criança são vistos por muitos como uma situação urgente.

Entretanto, o que tornará um grande desafio para o profissional de enfermagem. É importante ressaltar algumas descrições a respeito dos cursos superiores em enfermagem, sustentando que o processo de formação de profissionais em enfermagem, em oportunizar possibilidades de responderem às necessidades de atenção psicossocial aos portadores de sofrimento psíquico que vivenciam o $\mathrm{TDAH}^{6}$. Contudo, considerando-se a integração da teoria e a prática. Nesta perspectiva, a integração da Enfermagem Psiquiátrica e Saúde Mental, desempenham um importante papel.

Para os autores os profissionais demonstram seu entendimento a respeito do problema, ao apontar ferramentas e técnicas pedagógicas. Dessa maneira, o cuidado é constituído pela forma com que os profissionais possam superar os desafios que expressam a apreensão que transpõe o físico e engloba o sofrimento psíquico das crianças.

Dessa forma, ao construir afirmativas de diagnósticos e intervenções de enfermagem para o paciente infantil acometido de transtornos de TDAH. No entanto, os dados endossam ao descrever a importância do profissional de enfermagem ao identificar possíveis transtornos relacionados à saúde mental da criança, através de exames físicos e clínicos simples, ainda na unidade básica de saúde 7 .

Salienta-se que o profissional de enfermagem, quanto sujeito porta-se perante o processo de trabalho da atenção básica. Isto cria uma forma específica de cuidar na enfermagem, tem importante papel na identificação do transtorno mental infantil através de possíveis sinais e sintomas detectados, conforme o transtorno apresentado.

Os futuros profissionais de enfermagem em sua maioria, apesar de identificarem patologias de ordem de transtorno mental. E, também, apesar de reconhecerem a importância na atenção da enfermagem que a criança recebe nesta área. Pode-se dizer que muitos desses profissionais acabam acuados ao se sentirem incapacitados para cuidar pacientes infanto juvenil com problemas de saúde mental ${ }^{8}$.

Pode-se dizer que os recém-formados, em sua maioria, apesar de identificarem patologias de ordem mental. É importante pontuar que na maioria das vezes os profissionais de enfermagem não são capacitados para lidar com essas situações, não estar aptos a prestarem o devido cuidado a esta população.

Nesta mesma linha, é interessante constatar que o profissional de enfermagem deve fornecer o suporte para realizar o encaminhamento da criança e sua família 


\begin{tabular}{|c|c|c|c|c|c|c|}
\hline & TÍTULO & AUTOR(ES) & OBJETIVO & MÉTODO & CONCLUSÃO & ANO \\
\hline Artigo 1 & $\begin{array}{l}\text { Vida e sexualidade } \\
\text { de mulheres estomi- } \\
\text { zadas: subsídios à } \\
\text { enfermagem. }\end{array}$ & $\begin{array}{l}\text { Marina S; Camila } \\
\text { D; Giovana C. }\end{array}$ & $\begin{array}{l}\text { O estudo teve por ob- } \\
\text { jetivo conhecer como } \\
\text { a estomização inter- } \\
\text { fere na expressão da } \\
\text { sexualidade de mu- } \\
\text { lheres estomizadas. }\end{array}$ & $\begin{array}{l}\text { Pesquisa qualita- } \\
\text { tiva. }\end{array}$ & $\begin{array}{l}\text { É importante que os } \\
\text { profissionais da saú- } \\
\text { de implementem es- } \\
\text { tratégias educativas } \\
\text { para mulheres esto- } \\
\text { mizadas e seus com- } \\
\text { panheiros. }\end{array}$ & 2016 \\
\hline Artigo 2 & $\begin{array}{c}\text { Qualidade de vida } \\
\text { da pessoa estomiza- } \\
\text { da: relação com os } \\
\text { cuidados prestados } \\
\text { na consulta de enfer- } \\
\text { magem de estoma- } \\
\text { terapia. }\end{array}$ & $\begin{array}{l}\text { Liliana S; Amân- } \\
\text { cio A; Elisabete P. }\end{array}$ & $\begin{array}{l}\text { Analisar a relação } \\
\text { entre a Qualidade de } \\
\text { Vida (QV) e os cuida- } \\
\text { dos prestados na con- } \\
\text { sulta de enfermagem } \\
\text { de estomaterapia. }\end{array}$ & $\begin{array}{l}\text { Estudo descritivo- } \\
\text { correlacional. }\end{array}$ & $\begin{array}{l}\text { Existe relação esta- } \\
\text { tística entre QV, o } \\
\text { tipo de estomia e par- } \\
\text { ticipação na consulta } \\
\text { de enfermagem de } \\
\text { estomaterapia. }\end{array}$ & 2018 \\
\hline Artigo 3 & $\begin{array}{l}\text { Percepção dos } \\
\text { pacientes com } \\
\text { estomia intestinal em } \\
\text { relação às mudanças } \\
\text { nutricionais e estilo } \\
\text { de vida. }\end{array}$ & $\begin{array}{l}\text { Clarissa M; Luana } \\
\text { B; Maria E; et al. }\end{array}$ & $\begin{array}{l}\text { Descrever as percep- } \\
\text { ções dos estomizados } \\
\text { intestinais sobre as } \\
\text { mudanças no estilo } \\
\text { de vida e aspectos } \\
\text { nutricionais. }\end{array}$ & $\begin{array}{l}\text { Estudo explora- } \\
\text { tório e descritivo, } \\
\text { com abordagem } \\
\text { qualitativa. }\end{array}$ & $\begin{array}{l}\text { Há a necessidade de } \\
\text { acompanhamento } \\
\text { nutricional e psico- } \\
\text { lógico aos estomiza- } \\
\text { dos. }\end{array}$ & 2019 \\
\hline Artigo 4 & $\begin{array}{c}\text { Tecnologia para } \\
\text { o autocuidado da } \\
\text { saúde sexual e repro- } \\
\text { dutiva de mulheres } \\
\text { estomizadas. }\end{array}$ & $\begin{array}{l}\text { Andressa F; Ana } \\
\text { K; Francisca M; } \\
\text { et al. }\end{array}$ & $\begin{array}{l}\text { Validar uma tecno- } \\
\text { logia do tipo cartilha } \\
\text { impressa para o au- } \\
\text { tocuidado na saúde } \\
\text { sexual e reprodutiva } \\
\text { de mulheres estomi- } \\
\text { zadas. }\end{array}$ & $\begin{array}{l}\text { Estudo metodoló- } \\
\text { gico. }\end{array}$ & $\begin{array}{l}\text { A tecnologia educati- } \\
\text { va em questão foi va- } \\
\text { lidada segundo con- } \\
\text { teúdo e aparência, } \\
\text { constituindo-se um } \\
\text { recurso adequado, } \\
\text { confiável e de fácil } \\
\text { compreensão. }\end{array}$ & 2016 \\
\hline Artigo 5 & $\begin{array}{l}\text { A visão dos enfer- } \\
\text { meiros sobre as } \\
\text { práticas educativas } \\
\text { direcionadas as pes- } \\
\text { soas estomizadas. }\end{array}$ & $\begin{array}{c}\text { Vanessa C; Norma } \\
\text { V; Carolina C; } \\
\text { et al. }\end{array}$ & $\begin{array}{l}\text { Analisar o ponto de } \\
\text { vista dos enfermeiros } \\
\text { sobre as ações educa- } \\
\text { tivas realizadas com } \\
\text { as pessoas estomiza- } \\
\text { das. }\end{array}$ & $\begin{array}{l}\text { Pesquisa qualitati- } \\
\text { va e exploratória, } \\
\text { interpretativa e crí- } \\
\text { tica. }\end{array}$ & $\begin{array}{l}\text { Os enfermeiros apre- } \\
\text { sentavam uma prá- } \\
\text { tica humanizada e } \\
\text { objetivavam tornar o } \\
\text { processo educativo } \\
\text { mais dinâmico. }\end{array}$ & 2017 \\
\hline Artigo 6 & $\begin{array}{l}\text { Qualidade de vida } \\
\text { de pessoas com } \\
\text { estomias intestinais } \\
\text { de eliminação. }\end{array}$ & $\begin{array}{l}\text { Cynthia R; Elaine } \\
\text { M; Maria H; et al. }\end{array}$ & $\begin{array}{l}\text { Objetivou-se avaliar } \\
\text { a qualidade de vida } \\
\text { de pessoas com es- } \\
\text { tomias intestinais de } \\
\text { eliminação. }\end{array}$ & $\begin{array}{l}\text { Estudo descritivo e } \\
\text { transversal. }\end{array}$ & $\begin{array}{l}\text { As estomias intesti- } \\
\text { nais de eliminação } \\
\text { interferem na quali- } \\
\text { dade de vida, princi- } \\
\text { palmente nos âmbi- } \\
\text { tos físico e social. }\end{array}$ & 2017 \\
\hline Artigo 7 & $\begin{array}{l}\text { Aspectos sociode- } \\
\text { mográficos e clínicos } \\
\text { de estomizados in- } \\
\text { testinais provisórios. }\end{array}$ & $\begin{array}{l}\text { Janderson C; } \\
\text { Adriana P; } \\
\text { Katia J; et al. }\end{array}$ & $\begin{array}{l}\text { Caracterizar aspectos } \\
\text { sociodemográficos e } \\
\text { clínicos de estomiza- } \\
\text { dos intestinais provi- } \\
\text { sórios. }\end{array}$ & $\begin{array}{l}\text { Estudo transversal, } \\
\text { de natureza quan- } \\
\text { titativa. }\end{array}$ & $\begin{array}{l}\text { O conhecimento das } \\
\text { características da } \\
\text { população atendida } \\
\text { contribui para o pla- } \\
\text { nejamento da assis- } \\
\text { tência }\end{array}$ & 2017 \\
\hline Artigo 8 & $\begin{array}{c}\text { Cuidado integral à } \\
\text { pessoa estomizada } \\
\text { na Atenção Básica } \\
\text { - Conhecimento e } \\
\text { atuação do enfer- } \\
\text { meiro. }\end{array}$ & $\begin{array}{c}\text { Lidiaine N; Ana P; } \\
\text { Maria N. }\end{array}$ & $\begin{array}{l}\text { Apreciar o conhe- } \\
\text { cimento e a atuação } \\
\text { do enfermeiro no } \\
\text { cuidado à pessoa es- } \\
\text { tomizada na atenção } \\
\text { básica. }\end{array}$ & $\begin{array}{l}\text { Estudo com caráter } \\
\text { qualitativo, explo- } \\
\text { ratório e descriti- } \\
\text { vo. }\end{array}$ & $\begin{array}{l}\mathrm{O} \text { ensino de enfer- } \\
\text { magem e a educação } \\
\text { permanente poderão } \\
\text { contribuir para uma } \\
\text { atuação competente e } \\
\text { eficaz de cuidado in- } \\
\text { tegral ao estomizado. }\end{array}$ & 2017 \\
\hline Artigo 9 & $\begin{array}{c}\text { Autoimagem e } \\
\text { autocuidado na } \\
\text { vivência de pacientes } \\
\text { estomizados: o olhar } \\
\text { da enfermagem. }\end{array}$ & $\begin{array}{c}\text { Daniela A; Rebeca } \\
\text { C; Naua R; et al. }\end{array}$ & $\begin{array}{l}\text { Analisar a percepção } \\
\text { de pacientes esto- } \\
\text { mizados sobre a sua } \\
\text { autoimagem e auto- } \\
\text { cuidado. }\end{array}$ & $\begin{array}{l}\text { Estudo explora- } \\
\text { tório, descritivo e } \\
\text { qualitativo. }\end{array}$ & $\begin{array}{l}\text { Recomenda-se que a } \\
\text { enfermagem se apro- } \\
\text { funde nos conheci- } \\
\text { mentos sobre esto- } \\
\text { mas, principalmente } \\
\text { em relação ao auto- } \\
\text { cuidado e aceitação } \\
\text { do paciente. }\end{array}$ & 2017 \\
\hline
\end{tabular}


Tabela 2. Apresenta o resumo do resultado principal de cada artigo, sintetizando as ideias dos autores acerca das ações do profissional de enfermagem nas orientações de enfermagem para a criança e a família frente ao conflito de aprendizado devido TDAH.

\begin{tabular}{|c|c|c|}
\hline $\mathbf{N}^{0}$ & TÍTULO & RESUMO \\
\hline 1 & $\begin{array}{l}\text { Ensino da enfermagem psiquiátrica/saúde mental: sua in- } \\
\text { terface com a Reforma Psiquiátrica e diretrizes curricula- } \\
\text { res nacionais. }\end{array}$ & $\begin{array}{l}\text { Não bastam apontar questões técnicas relativas ao conteúdo de ensino, } \\
\text { procedimentos didáticos, métodos e técnicas pedagógicas; é necessário } \\
\text { superar os desafios e implementar as mudanças, pautando-se numa nova } \\
\text { perspectiva, e ousando colocar em questão a natureza do saber e das } \\
\text { práticas institucionais psiquiátricas. }\end{array}$ \\
\hline 2 & $\begin{array}{l}\text { Concepções do enfermeiro acerca de transtorno mental in- } \\
\text { fantil em atenção básica }\end{array}$ & $\begin{array}{l}\text { Quando algum sinal ou sintoma relevante é identificado, encaminha- } \\
\text { se o caso para o médico da atenção básica e, a partir daí, inicia-se os } \\
\text { serviços de referência e contra referência. O enfermeiro, quanto sujeito } \\
\text { atuante no processo de trabalho da atenção básica, tem importante papel } \\
\text { na identificação do transtorno mental infantil através de possíveis sinais } \\
\text { e sintomas detectados durante a consulta de C\&D. }\end{array}$ \\
\hline
\end{tabular}

Formação de acadêmicos de enfermagem para o cuidado Verificou-se que as disciplinas Enfermagem em Saúde Mental e Saúde da saúde mental de crianças e adolescentes. da criança e do adolescente dão ênfase respectivamente ao "Cuidado em Saúde Mental" e "Saúde da Criança e do Adolescente" de forma isolada. Os acadêmicos, em sua maioria, apesar de identificarem patologias de ordem mental e reconhecerem a importância da Enfermagem nesta área, admitiram não estar aptos a prestarem o devido cuidado a esta população.

Dimensão cuidadora da enfermagem e da família na assis- Os resultados apontam que o trabalho realizado pela equipe tem sido tência criança hospitalizada procedimento centrado de forma que a interação com a criança e sua família. É tangencial no processo de cuidar no hospital em estudo. A família tem dividido cuidados, muitas vezes impostos pela equipe, e no tem sido envolvida no cuidado como coparticipe nem como objeto de cuidado.

Contribuições da atividade física para o tratamento psico- Os resultados indicaram que a prática de atividade física pode contribuir lógico do TDAH em crianças no curso do tratamento do transtorno de Déficit de atenção e hiperatividade através da utilização de metodologias e técnicas que auxiliem a criança a desenvolver o diálogo interno; aperfeiçoar as habilidades sociais; desenvolver o repertório de resolução de problemas; entre outros.

Concepções de profissionais da saúde sobre altas habili- Constatou-se que crianças as quais apresentam condutas mais ativas, em dades e transtorno de déficit de atenção e hiperatividade determinadas situações, ou são quietas e mesmo passivas, em outras, (TDAH) em crianças. não devem ser caracterizadas como patológicas e passíveis de medicalização, pois essas condições não são adequadamente avaliadas na escola e nos consultórios médicos e/ou psicológicos. Tais procedimentos podem ter erros e não permitir que crianças com capacidade elevada tenham oportunidades de se manifestarem.

A enfermagem e a promoção de saúde mental na escola: O projeto atuou como um propulsor às crianças na elaboração de seus reconhecimento e empoderamento das emoções sentimentos frente a situações corriqueiras, além de fortalecer a autoestima e a capacidade de adaptação ao meio escolar, exercitando o empoderamento. Além disso, nota-se que o contato estabelecido com as ações grupais de promoção em saúde possibilitou às acadêmicas o fortalecimento da atuação do profissional de enfermagem no território escolar.

Uso limitado e parcial do processo de enfermagem no cuidado estabeProcesso de enfermagem na saúde mental: revisão integra- lecido por meio da relação terapêutica que respeita a individualidade tiva da literatura do paciente. Observaram-se propostas de cuidados sistematizados para pacientes que apresentam aspectos patológicos no limite entre físico e psíquico, podendo ser uma resposta à influência da prática baseada em evidências.

Serviços de atendimento móvel de urgência frente às emer- Observou-se uma escassez de estudos sobre os serviços de atendimento gências psiquiátricas: uma revisão narrativa móvel de urgência frente às emergências psiquiátricas. Os serviços de urgência e emergência, quando prestam assistência à pessoa em crise psíquica, têm priorizado a sedação e o encaminhamento para o internamento hospitalar, reproduzindo o saber da psiquiatria tradicional. A dificuldade dos profissionais de saúde em atender a pessoa em situações de urgência e ou emergência psiquiátrica, por vezes está relacionada com a deficiente formação, e com a falta de educação permanente que abarque a saúde mental 
ao serviço de saúde. No entanto, essas questões devem ser abordadas pela enfermagem, que deverá apresentar os esclarecimentos necessários.

Deve aqui salientar que os usuários dos serviços de saúde mental enfrentam dificuldades com os profissionais de saúde em atender a pessoa em situações de atenção básica psiquiátrica. Em relação à promoção a saúde, por vezes está relacionada com a deficiente formação, e com a falta de preparo permanente que abarque a saúde mental ${ }^{9}$.

Diante do exposto acima, é importante que o profissional de enfermagem esteja atento, para observar e auxiliar. É importante que eles conheçam as melhores estratégias para o auxílio de seus filhos na organização e no planejamento das atividades. Tendo em vista que a família e a escola devem ser orientadas sobre como trabalhar melhor com estas crianças.

Nesta perspectiva apresentam os pressupostos em relação à dificuldade dos profissionais de enfermagem em atender criança em situações emergência psiquiátrica. No entanto, as prescrições de enfermagem vão fundamentar a orientação permanente que abarque a saúde mental.

Diante desses fatores deve-se apontar para a ausência de contato com temas relacionados aos cuidados da saúde mental durante a formação geral ${ }^{10}$. No entanto, pode afirmar que isso, contraria as noções de promoção da saúde promulgada pela OMS, além de levar em conta também na psicoterapia e, inclusive no contato da enfermagem com o paciente, garantindo o tratamento precoce dos transtornos identificados em crianças e adolescentes em instituições educacionais.

É celebre a esse respeito da importante reflexão ao lembrar que o despreparo dos profissionais de enfermagem na forma de abordagem criança e família no dia a dia na internação clínica ${ }^{11}$. Pode-se dizer que, como regra geral, faltam-lhes noções na área de conhecimento sobre transtorno mental que deem suporte para trabalhar com a saúde mental infantil, e para estabelecer processos efetivos de comunicação através de propostas oriundas da reforma psiquiátrica brasileira.

Para este cuidado ampliado ocorra, a intervenção da família é primordial em dividir os cuidados. Além disso, os autores trazem essa necessidade, de direcionar o foco, e que muitas vezes impostos pela equipe, e não tem sido envolvida no cuidado como coparticipe nem como objeto de cuidado na implementação do diagnóstico de enfermagem.

Entretanto, não é por acaso que a enfermagem procura, desde seu início enquanto profissão, acompanhar essas mudanças e redimensionar suas finalidades terapêuticas ${ }^{12}$.

Nesta perspectiva salienta-se que a busca de alternativas terapêuticas, tais como: os projetos sociais, as atividades esportivas e culturais, além do atendimento pedagógico na escola, que é uma forma de tratamento ${ }^{13}$. Partindo do princípio que o papel da enfermagem mudou signiticantemente nas várias atividades, levando em conta a orientação com os pais e o acompanhamento psicoterapêutico para a criança no sentido de compreender os conflitos que o afligem.

$\mathrm{Na}$ diversidade de abordagens constatouse que crianças as quais apresentam condutas mais ativas, em determinadas situações, não devem ser caracterizadas como patológicas de TDAH, e passíveis de medicalização. Entretanto, essas condições não são adequadamente avaliadas no ambiente educativo. Somente após um período de tratamento é possível conquistar e estabelecer um relacionamento que possa se tornar terapêutico.

Entretanto, existem diversas formas de psicoterapia, que variam com os objetivos proposto. É importante salientar os níveis de intervenções secundários em relação abordagens terapêuticas. Ao encontrar respostas, deve-se trazer a memória as referências das atividades que evidenciam, tais como esportes e ginásticos ${ }^{14}$. Neste sentido, partir da resposta da atividade física. Conforme os estudos, tal posição tem proporcionado uma melhora muito grande nas funções executivas da mente da criança, e se estendendo aos cuidados pedagógicos, tais como, na resolução de problemas, no planejamento de leitura e execução de tarefas. E acima de tudo estabelecendo a potencialização da memória de trabalho escolar.

Por essas razões, segundo os autores, os resultados indicaram que a prática de atividade física pode contribuir no curso do tratamento do transtorno de TDAH, através da utilização de metodologias e técnicas que auxiliem a criança a desenvolver o diálogo interno na busca de uma vida saudável. Neste sentido, surge a intenção do cuidar, iniciando pelo acolhimento.

Devo, no entanto chamar atenção para prática terapêutica, no sentido que muitos profissionais da saúde, sugerem o medicamento, como solução na maioria dos $\operatorname{casos}^{13}$. No entanto, os psicofármacos como são chamados, além de ser justificado na prescrição do medicamento, muitas das vezes trazendo prejuízos educacionais, sociais e emocionais vividos pela criança.

No cerne desta questão existe outra técnica muito utilizada no curso do tratamento do TDAH é a Autoinstrução, Autocontrole. É um método que objetiva a substituição de pensamentos desadaptativos pelos pensamentos adaptativos a partir do treino do diálogo interno ${ }^{14}$.

Diante disso, o relacionamento terapêutico é uma excelente ferramenta que promove de saúde mental em qualquer situação que exija acompanhamento intensivo ou semi-intensivo do profissional de enfermagem, seja na área da psiquiatria ou saúde mental, ou em qualquer outra área do conhecimento da enfermagem ${ }^{12}$.

Do que foi dito até aqui, os estudos evidenciaram que as atividades laborais da enfermagem pediátrica desde o ACP, e sua adaptação e a forma de participação 
no cuidado criança, não deixa de ser um processo que vem se constituindo na pratica assistencial ${ }^{11}$.

Fica evidente ao considerar a importância da Promoção de Saúde Mental para atender as demandas de saúde infanto-juvenis, faz-se importante conhecer as ações para fortalecer e potencializar os processos saudáveis das crianças ${ }^{15}$. Tais como: o empoderamento das emoções, pensamentos e reações comportamentais, principalmente em crianças com TDAH.

Não é difícil entender que, é fundamental o contato estabelecido com as orientações grupais de promoção em saúde, em que possibilitou os acadêmicos, no fortalecimento da atuação do profissional de enfermagem no espaço escolar.

Com base nas informações colhidas, atualmente, pode perceber o descompasso entre o ensino e a prática da enfermagem em saúde mental infanto-juvenil. Tendo em vista essa fragilização o que chama atenção pelo fato de que profissionais da atenção básica em saúde mental de crianças e adolescentes devem dar condições para que o profissional de enfermagem desenvolva habilidades científicas, humanísticas e técnicas, além de conhecimento com especificidade na área em questão ${ }^{8}$.

Ao que se refere à especialização pode-se dizer que o enfermeiro que tem a formação em psiquiatria, se utiliza de sua pessoa como recurso terapêutico para facilitar a mobilização dos recursos do paciente cujo objetivo é a promoção, manutenção ou recuperação da saúde mental como parte integral da saúde do indivíduo ${ }^{5}$.

Dessa forma, é fundamental procurar ter uma definição clara do problema, através da formulação de diagnósticos de enfermagem, da implementação de intervenções, que impliquem a criança que faz uso e a família como parceira voltada para o diálogo e a escuta qualificada. Esta compreensão pode contribuir, para que estes profissionais, principalmente o da enfermagem saibam lidar com o comportamento e, a situação psicossocial do usuário em crise de transtornos e da sua família ${ }^{9}$.

Espera-se dessa forma que no contexto da atenção primária, o profissional de enfermagem é o principal ator na execução das consultas de crescimento e desenvolvimento ${ }^{7}$. Tomando por base todos os exames clínicos e físicos relacionados ao desenvolvimento do infante, o profissional de enfermagem tem subsídios diante das propostas para investigar e analisar a presença de um possível transtorno mental.

É nesse ambiente que se espera que o profissional de enfermagem seja ele especialista ou não em pediatria, desempenhe cuidados de nível avançado, com segurança, competência e culturalmente responsivos às necessidades da criança e da família ${ }^{16}$.

Diante desses dados, deve aqui salientar que de certa forma há uma resistência em entender a necessidade do cuidado em saúde mental ainda no âmbito da criança. Fica evidente que assistência do profissional de enfermagem voltada para crianças acometidas por essas patologias é pautada no acolhimento terapêutico e nas orientações perante família. Sendo assim, os resultados dessas ações é a necessidade de quebras de paradigmas.

\section{Considerações finais}

Pretendeu-se através do presente trabalho ressaltar em reflexões as peculiaridades em torno da criança com TDAH, onde se acredita que é de suma importância o papel do profissional de enfermagem dentro instituição educacional e principalmente no cuidado da saúde mental dos educandos. Constatou-se ao pesquisar sobre o assunto em questão onde despertou o interesse pela temática.

No entanto, era importante pesquisar sobre a orientação da enfermagem e a criança em conflito de aprendizagem TDAH. Diante disso, a pesquisa teve como proposta principal identificar as atuações de enfermagem frente à criança com TDAH. É preciso ressaltar que os objetivos foram atendidos. Contudo, o estudo conseguiu demonstrar os dados relativos ao perfil de crianças com TDAH.

Neste caso, ressalta-se que a atenção às crianças brasileiras na área da saúde mental da criança e do adolescente constitui necessidade imperativa e com demanda crescente. Com efeito, a falta de serviços e especialistas nesta área é preocupante, fato que contribui para que os profissionais de enfermagem, de maneira geral, tenham grande dificuldade para encaminhar crianças com transtorno de TDAH.

Pode-se perceber que os diagnósticos de enfermagem referentes às crianças com TDAH estão ligados diretamente ao comprometimento das funções mentais e emocionais e, também, relacionados aos aspectos educacionais no âmbito do aprendizado. E com isso, deve-se ressaltar ao preconizar a importância da atenção básica no âmbito da saúde mental. Em destaque o profissional de enfermagem em uma atuação de agente terapêutico.

Entretanto, a análise das definições da literatura permitiu identificar os atributos essenciais que diz respeito à criança com TDAH. Mediante o levantamento dos sinais e sintomas de transtornos mentais em crianças no âmbito escolar.

Por meio do processo de enfermagem, especificamente dos diagnósticos de enfermagem, base para realização do plano de intervenções e assim, auxiliam na recuperação do processo saúde mental do infante. É preciso ressaltar que papel do enfermeiro, sim, avaliar e realizar junto com outros profissionais, principal o psicólogo, na manutenção das condições de aprendizagem do paciente. 
Deste modo, o ponto norteador para o levantamento e planejamento da assistência. No entanto, permite o melhor direcionamento da atenção às necessidades da criança com TDAH. Todavia, é necessário o levantamento desses diagnósticos uma vez que, estes auxiliam na promoção e estabelecimento de intervenções que foquem em cada problema detectado no paciente com intuito de alcançar a sua recuperação no âmbito da saúde mental.

Entende-se que, a prevenção em saúde mental deve incluir atividades que propiciem o autoconhecimento voltados para as crianças e para os pais, auxiliando a essa criança a perceber que estão vivendo a mesma situação, ou seja aquilo que está ocorrendo com ela. Contudo, podem-se criar neles redes de proteção, enfatizando a aceitação das diferenças, entre os colegas de escola, ao estimulo e o aprendizado.

Entretanto, constata que a busca de alternativas terapêuticas, tais como: os projetos sociais, as atividades esportivas e culturais, além do atendimento pedagógico na escola, que é uma forma de tratamento. Neste sentido, verificou-se que a construção de atividade física e esportiva, segundo alguns autores, mostrou-se eficaz para avaliação das informações transmitidas.

A escolha de atividades adequadas para determinadas faixas etárias é relevante. Conforme os estudos, tal posição em relação à criança tem proporcionado uma melhora muito grande nas funções executivas da mente do mesmo, e se estendendo aos cuidados pedagógicos, tais como: respondendo resolução de problemas, no planejamento de leitura e execução de tarefas. E acima de tudo estabelecendo a potencialização da memória de trabalho escolar.

De igual importância é a orientação que o profissional de enfermagem ao conduzir a atividade terapêtica que uma excelente ferramenta promotora de saúde mental em qualquer situação que exija acompanhamento intensivo ou semi-intensivo. Deve-se ressaltar que a questão é complexa, em que as crianças com TDAH, podem ser reabilitadas ao convívio saudável, mesmo dentro da instituição educacional.

Ressaltar aqui, que ao ajuda-las, é importante considera-las integramente, compreendendo que elas apresentam tanto dificuldades, ou sintomas, como capacidades. Diante desses dados, o trabalho da enfermagem pediátrica e sua adaptação e a forma de participação no cuidado criança, não deixa de ser um processo que vem se constituindo na pratica assistencial.

Esta compreensão pode contribuir, para que este profissional de enfermagem saiba lidar com o comportamento e, a situação psicossocial do usuário em crise de transtornos e da sua família.

Neste contexto esses dados podem ser utilizados para apoiar a tomada de decisão clínica a partir do profissional de enfermagem, a respeito de qualquer transtorno. No cerne desta questão, deve debruçar ao analisar os cuidados de enfermagem em que os resultados alcançados com as crianças com TDAH, ao desenvolver políticas de saúde e suscitar conhecimento pela investigação, e o interesse existencial em torno das questões de TDAH ligado a saúde, a um viver saudável e feliz de uma criança em pleno desenvolvimento.

De acordo com a metodologia foi realizada uma buscanaliteratura utilizando-sea BVS (Biblioteca Virtual em Saúde), através de levantamentos bibliográficos. É importante ressaltar as dificuldades encontradas no contexto do trabalho, diante da metodologia proposta, esse trabalho poderia ser aprofundado devido amplo gama de literatura, assim a ciência médica em enfermagem vai se aproximando dos fatos reais, ligados a saúde mental.

Recomenda-se mais aprofundamento de pesquisas sobre o assunto em questão. Observa-se que as literaturas de enfermagem que abordam o tema são escassas levando em consideração que a TDAH é um agravo de saúde pública. Fato esse constatado ao encontrar poucos artigos que se referem à assistência clínica a esses pacientes (crianças), pois muitos estudos tratam das terapêuticas medicamentosas e quadro clínico.

Ora em tese, com a elaboração desse trabalho, espera-se motivar os profissionais de enfermagem a se especializar em colaborar para o seu próprio aperfeiçoamento. Sendo assim, acolher e escutar são ações esperadas por parte do profissional de enfermagem, em que este se encontra em posição privilegiada, por estar próximo ao paciente. Fica evidente que valorizar e estimular as habilidades e capacidade de aprendizado, para que a criança com TDAH encontrem maneiras de viver no ambiente escolar, e que tragam maior satisfação na sua dinâmica de vida.

\section{Referências}

1. Opas. Organização Pan Americana da Saúde. Transtornos Mentais, 2018. [Acesso em 2019 Jun.23]. Disponível em: https://www.paho.org/bra/ index.php?option $=$ com content $\&$ view $=$ article $\&$ id $=5652$ :folha-informativatranstornos-mentais \&Itemid $=839$.

2. Peixoto ALB, Rodrigues MMP. Diagnóstico e tratamento de TDAH em crianças escolares, segundo profissionais da saúde mental. Aletheia. [internet].2008 Jul./Dez[Acesso em 2019Jun15]. (28): 91-103. Disponível em: http://pepsic.bvsalud.org/pdf/aletheia/n28/n28a08.pdf.

3. Costa R. A polêmica do Déficit de atenção. [internet]. [Acesso em 2019 Jun.15] Ed. 2637, 24/07, n²229. Disponível em: https:/istoe.com. br/224791_A+POLEMICA+DO+DEFICIT+DE+ATENCAO/.

4. Gil AC. Como elaborar projetos de pesquisa. $4^{\circ}$. ed. São Paulo: Atlas, 2002 .

5. Garcia RF, Freitas MIP, Lamas JLT, Toledo VPT. Processo de enfermagem na saúde mental: revisão integrativa da literatura. Revista Brasileira de Enfermagem [internet]. 2017 Jan/Fev. [Acesso em 2020 Abril 15].70(1) 220-230. Disponível em: https://www.redalyc.org/ pdf/2670/267049841028.pdf.

6. Fernandes J F, Sandigursky D, Silva RMO, Amorim AB, Teixeira 
GAST, Araújo MCF. Ensino da enfermagem psiquiátrica e saúde mental: sua interface com a Reforma Psiquiátrica e diretrizes curriculares nacionais. Rev. esc. enferm. USP [internet]. 2009 Dez [Acesso em 2020 Abri. 07].43 (4):962-8. Disponível em: https://www.scielo.br/pdf/reeusp/v43n4/ a31v43n4.pdf.

7. Maia MPM, Valença CN, Sobreira MVS. Concepções do enfermeiro acerca de transtorno mental infantil em atenção básica. Revista Rede de Cuidados em Saúde. [internet].2017[Acesso em 2020 Abri.07].11,(1):1-22. Disponível em: http://publicacoes.unigranrio.edu.br/index.php/rcs/issue/ view/241.

8. Sá NKCM, Junior IGC, Carvalho JW, Alencar DC, Campelo LLCR. Formação de acadêmicos de enfermagem para o cuidado da saúde mental de crianças e adolescentes. Revista Eletrônica Acervo Saúde. [internet]. 2020 Fev., [Acesso em 2020 Abri 07].Sup.44:p.1-12. Disponível em: https://doi. org/10.25248/reas.e3093.2020.

9. Souza AS, Cortes HM, Pinho PH. Serviços de atendimento móvel de urgência frente às emergências psiquiátricas: Uma revisão narrativa. Revista Portuguesa de Enfermagem de Saúde Mental. [internet]. 2018 Dez. [Acesso em 2020 Abri 17 ].(20):72-80. Disponível em: doi: 10.19131/rpesm.0229.

10. Baião JJ, Marcolan JF. Labirintos da formação em enfermagem e a Política Nacional de Saúde Mental. Rev Bras Enferm [internet].2020. [Acesso em 2020 Jul 27]. 73(Suppl 1):1-8. Disponível em: https://www. scielo.br/pdf/reben/v73s1/pt_0034-7167-reben-73-s1-e20190836.pdf.

11. Pimenta EAG, Collet N. Dimensão cuidadora da enfermagem e da família na assistência à criança hospitalizada. Rev. Soc. Bras. Enferm. Ped. [internet] 2008 Jul [Acesso em 2020 Abri 07] 8,(1):7-11. Disponível em: https://sobep.org.br/revista/images/stories/pdf-revista/vol8-n1/v.8_n.1-art1. pesq-dimensao-cuidadora-da-enfermagem.pdf.

12. Kantorskia LP, Pinho LB, Saeki T, Souza MCBM. Relacionamento terapêutico e ensino de enfermagem psiquiátrica e saúde mental: tendências no Estado de São Paulo. Rev Esc Enferm USP.[internet].2005 Mar[Acesso em 2020 Abri 07] 39(3):317-24. Disponível em: https://www.scielo.br/pdf/ reeusp/v39n3/10.pdf.

13. Rondini CA, Incau C, Martins RA. Concepções de profissionais da saúde sobre altas habilidades e transtornos de déficit de atenção e hiperatividade (TDAH) em crianças. Revista Educação e Cultura Contemporânea. [internet]. 2016. [Acesso em 2020 Abri 15].13(32):15270.Disponível em: http://periodicos.estacio.br/index.php/reeduc/article/ view/938/1242.

14. Daou M, Pergher GK. Contribuições da atividade física para o tratamento psicológico do TDAH em crianças. Revista de Psicologia da IMED. [internet]. 2015 [Acesso em 2020 Abri 15].7(1): 42-51. Disponível em: https:// www.researchgate.net/profile/Giovanni_Pergher/publication/280570212_ Contribuicoes da Atividade Fisica para o Tratamento Psicologico do TDAH_em_Criancas/links/59 b $78098 \mathrm{aca} 2 \overline{7} 2 \overline{2} 453 \mathrm{a} 56 \mathrm{c} 18 / \bar{C}_{\text {Contribuicoes-da- }}$ Atividade-Fisica-para-o-Tratamento-Psicologico-do-TDAH-em-Criancas. pdf.

15. Braga GC, Ferreira MJ, Antoniolli D, Tigre JR, Auda JM, Signor M. Et al. A enfermagem e a promoção de saúde mental na escola: reconhecimento e empoderamento das emoções. Rev. Soc. Bras. Enferm. Ped. [internet]. 2005, Jun.[Acesso em 2020 Mar 20 ].15,(1):60-6. Disponível em: https://sobep. org.br/revista/images/stories/pdf-revista/vol15-n1/vol_15_n_2-relato-deexperiencia-1.pdf.

16. Cruz BA, Lemos FCS, Piani PPF, Brigagão JIM. Uma crítica à produção do TDAH e a administração de drogas para crianças. Estudos de Psicologia. [internet]. 2016 Jul/Set. [Acesso em 2019 Jun 23]. 21 (3) :282292. Disponível em: https://www.redalyc.org/pdf/261/26149979006.pdf 